
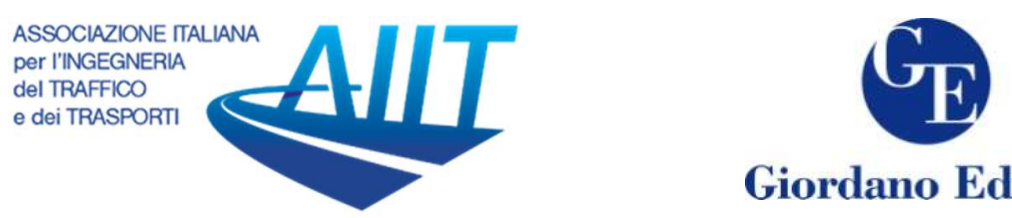

Giordano Editore

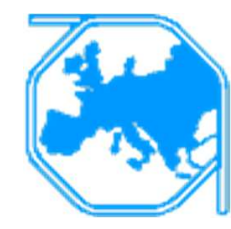

\title{
Internet of Things as an optimization tool for Smart Airport concept
}

\author{
Dominik Mrňa ${ }^{1 *}$, Benedikt Badánik ${ }^{1}$, Andrej Novák ${ }^{1}$ \\ ${ }^{1}$ Air Transport Department, University of Žilina, Univerzitná 8215/1 01025 Žilina, Slovakia.
}

\begin{abstract}
This paper covers the aspects of implementation of the Internet of Things concept into airport operations. It suggests areas that would be closely related to the Internet of Things. These areas mainly concern the handling of passengers or baggage and would be able to speed up the whole process significantly. The second part concerns the increase of passenger comfort by providing various information during their stay at the airport. This new system could significantly improve the quality of travel. In the last part, this paper discusses options for implementation of the concept at various selected airports. It includes information on readiness of these airports for digital transformation and availability of the digital tools for such a transformation.
\end{abstract}

Keywords: Internet of Things, Smart Airport, IoT components.

\section{Introduction}

Despite the decreasing demand for air transport caused by the COVID-19 pandemic, there is a need to constantly improve the various passenger handling processes at airports. As the demand for air transport continued to increase before the pandemic, one of the main challenges was to maintain the quality of the services needed (Correia, 2008; Morrison, 2009). The quality of such services is usually measured by the time required and level of comfort that passengers have (Kotopouleas and Nikolopoulou, 2018). One of the new possibilities to improve passenger comfort at airports is the use of the so-called Internet of Things. Incorporation of The Internet of Things into the airport management provides great benefits for airport operators. This paper suggests a new concept of how this system could be used to optimize passenger handling processes. These processes will be closely linked to the concept of Smart City. Internet of Things is a new computing paradigm that assigns to Internet-connected object the ability to send and receive data to perform specific task [Atzori et al., 2009; International Telecommunication Union, 2005; Bouyakoub et al., 2017). The mobile device needs a network connection to satellite

\footnotetext{
* Corresponding author: Dominik Mrňa (dominik.mrna@stud.uniza.sk)
} 
navigation for precise localization ( $\mathrm{Ni}$ et al, 2018), or a connection to another monitoring device. The term Smart Airport represents the integration of technology with the airport environment and provides to all stakeholders the opportunity to use the full range of technologies (Samy, 2017; ICES, 2016). Not only this concept represents the most efficient way to manage continuous flow of passengers (and goods) through the airport during normal operation, it also helps to secure continuous flow of passengers at the time of operational disruptions. This model largely depends on 3 factors:

- Self-service devices for passengers,

- Mobility,

- Collaborative decision making (Samy, 2017; SITA, 2011).

This evolving trend is leading passengers to reduce interactions with airport staff in favour of automated contact points and it leads to a radical restructuring of air transport processes and infrastructure (Samy, 2017).

There is very limited attention paid to the use of Internet of Things as a Smart Airport tool for passenger flow optimization during airport access and check-in process in the literature. For example, there is particular attention paid to the passenger flows at airports, as outlined by Mat'aš and Novák (2008) in their Models of Processes and Components of Air Passenger Flow Models. The term smart public transport in connection with smart city is used by Chaudhary et al. (2016) in the paper Finding occupancy in buses using crowdsourced data form smartphones. The use of modern technologies at airports for needs of passenger's handling is generally discussed by Samy (2017) in his paper Studying of traveler's use of self-check-in technologies in smart airports. Bouyakoub et al. (2017) deal with the use of the IoT for the needs of the airport management system in the paper Smart airport: an IoT-based Airport Management system. This paper considers the airport as a whole and tries to find the way to make the journey of passengers as smooth as possible. AlMashari et al. (2018) introduce and IoT-based smart airport mobile application interface in the paper IoT-based Smart Airport Solution.

\section{Use of the IoT at airports}

The first option where data form the IoT could be used is to optimize the use of checkin counters and security check points. A key input in this process is information obtained for this purpose from various data sources (Koman et al., 2018). This data would be based on number of passengers heading to the airport. The passenger sorting model cannot be used as model of passenger's arrival to the airport because it requires strong assumptions such as a stable arrival rate and thus does not capture the dynamic of passenger arrivals as well (Mat'aš and Novák, 2008). The arrival time of passengers is considered as a random variable. The distribution of passengers arriving to a check-in counters (security check points) varies according to the time of day, day of the week, airport, season, and type of passenger (Alodhaibi, Burdett and Yarlagadda, 2019). Therefore, from this point of view, is seems to be a better option to collect data of the occupancy from buses, trains, subways, cars from the passengers themselves using their smartphones (Chaudary et al., 2016). 


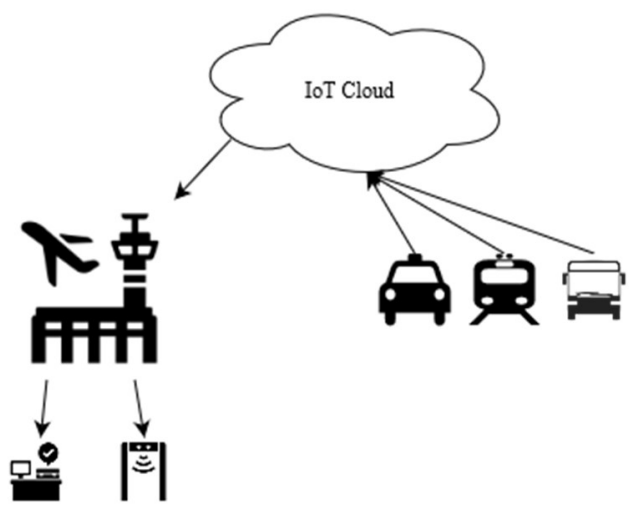

Figure 1: Basic concept of data sharing using IoT cloud.

Source: Authors.

This data from traffic management systems, sensors at busses / trains / subway / tram stops / vehicles or directly form passengers, would then be stored in cloud storage of the IoT, where airport staff would be able to access it and find out what is the actual number of passengers heading to the airport at given time of the day. Then the airport would use the information to determine the exact number of staff needed for the airport handling processes (outlined in Figure 1).

Airlines are also expected to share their data on passengers that are due to depart from specific airport. This data could then be compared with the data on number of passengers traveling in various means of public transportation to sort out the exact number of passengers heading to the airport. This information will lead to optimized use of airport staff for initial passenger processing at airport.

\subsection{Use of the IoT for check-in and security.}

There could be widespread use of Radio Frequency Identification (RFID) transmitters on baggage tags, all check-in counters could be open simultaneously for all airlines. RFID provide remote identification and do not require line of sight, unlike barcode technology (Want, 2006). This includes the use of traditional check-in counters or self-service checkin kiosks, which allow airport operator to reduce the number of airport staff (Lee and Lyu, 2019; Meuter et al., 2000). The more such check-in counters will be available, the smaller waiting queues will be formed (Štefánik, 2009). Such an RFID tag would then contain the passenger data, information on origin airport and arrival airport and the flight number. It could be used not only to track baggage but also to track the position of passengers who have not arrived at the departure gate yet (Baskoro et al., 2017). Such an RFID tracking chip could be placed on a printed boarding pass or on a baggage tag. In the baggage sorting process, such a system would not use label scanners for sorting, but could work with a light signal (red, green) to indicate to the employee which baggage to load to the aircraft or not (green yes, red no). IATA (2019) claims that when RFID transmitters are used, reading accuracy is $99.98 \%$, which is significantly better than the barcodes used today. Based on modern messaging standards, this system will allow airlines to proactively act in case of potential for baggage mishandling. Therefore, IATA believes that a combination of RFID and modern standards could reduce baggage mishandling by $25 \%$. In case of mishandling, passenger could know the exact position of his/her baggage. 
IATA (2019) therefore recommends to airports incorporate the use of RFID technology for baggage handling into their infrastructure. Also, for handling staff is recommended to start using RFID technology to replace operations requiring manual tracking wherever it is possible.

Time required for check-in may vary depending on number of checked bags a passenger is willing to check-in and the way the passenger is to check-in for the flight (no checked bags and boarding passes printed at home usually saves a lot of time at airport). Some low-cost carriers even require passengers to check-in online and they only process their checked bags at the airport (there are self-drop-off kiosks available at some airports what makes the whole process even faster). The whole possible process is shown in the flowchart in Figure 2.

Figure 2: Flowchart of passenger's options during handling process.

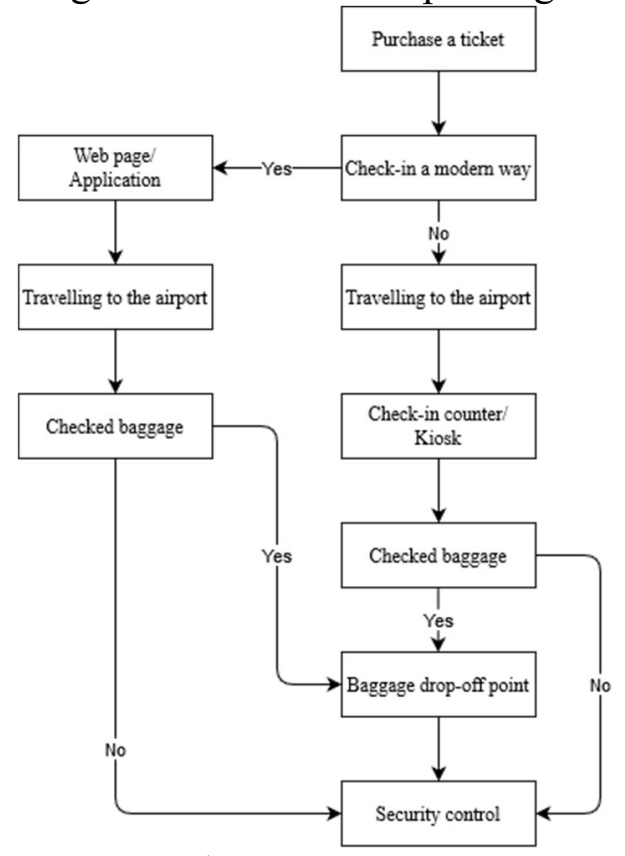

Source: Authors.

Considering the outlined procedures (Figure 2) and real-time data from the IoT cloud, the total number of individual passengers (located at certain service points at airport) could be predicted (Table 1). This would allow optimized distribution of airport staff at the service points and predictable number of service counters to be open.

Table 1: Passneger handling options based on flowchart in Figure 2

\begin{tabular}{lccc}
\hline & $\begin{array}{c}\text { Check-in } \\
\text { counter }\end{array}$ & $\begin{array}{c}\text { Online check- Baggage drop- } \\
\text { in }\end{array}$ \\
\hline Passenger 1 & $\bullet$ & & $\bullet$ \\
Passenger 2 & $\bullet$ & & \\
Passenger 3 & & $\bullet$ & $\bullet$ \\
Passenger 4 & & $\bullet$ & \\
\hline
\end{tabular}

Source: authors 
Based on the statistics of Ashford, Mumayiz, Wright (2011) and Cheng 2014):

- $90 \%$ of passengers arrive at the airport 60 minutes before the time of departure,

- Business travellers arrive at the airport late as leisure travellers,

- Peak in the morning is shorter and busier than in the evening.

Of course, the whole system cannot rely on statistical data only. It uses the formula (1) to calculate the time of arrival of passengers to the airport based on location (distance from the airport) and speed of traveling

$$
t_{\text {time of arrival to the airport }}=\frac{\text { distance from the airport }}{\text { speed of traveling }}
$$

System calculates the approximate time of arrival of a group of passengers or the largest group of passengers to the airport. The formula (1) shows more accurate and realistic values which leads to optimized planning of airport staff. Furthermore, the system uses data on the approximate time of arrival of passengers at individual service points. Such data would again be based on distance and average speed. The distance could be monitored in many ways. Either using GPS modules on passenger mobile devices, or by the use of WiFi, Bluetooth, and RFID signal from sensors (ACI, 2013) located either at public transport stops or at the main entrances to the terminal, or other stations located in the airport building. With the exact number of passengers and the known value of the terminal area, the average walking speed of the passengers can be calculated, taking into account the free area suitable for walking between individual posts. The larger the space around the passenger, the higher the walking speed. This relationship, outlined in figure 3 was discovered by Štefánik (2009).

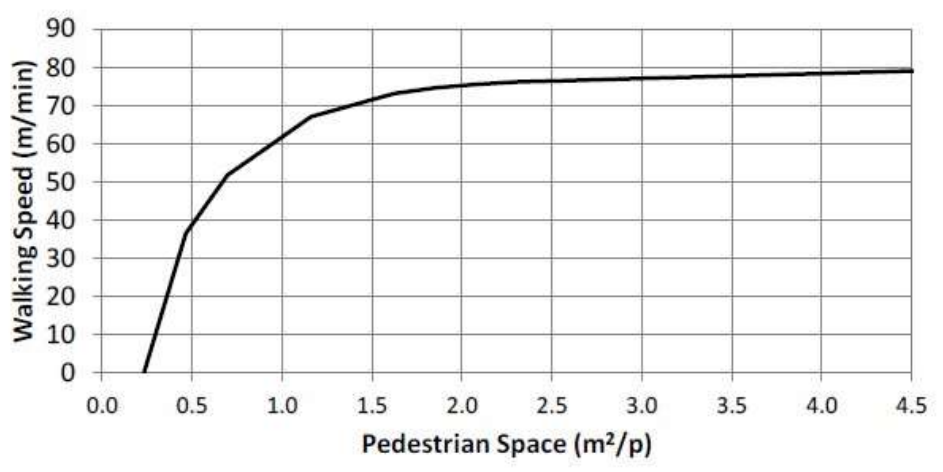

Figure 3: Graph with dependence of walking speed on pedestrian space.

Source: Štefánik.

A speed of 10 meters/minute represents a speed of approximately $0.6 \mathrm{~km} / \mathrm{h}$. A walking speed of passengers could be calculated based of the current number of persons in the terminal and the known value of the terminal area using formula (2)

$$
\text { pedestran space }=\frac{\text { known value of terminal area }}{\text { current number of persons in terminal }}
$$

This data would then enter into modeling system, which would be used to calculate the time of arrival to each airport service point. It works with the current known distance of the group of people and the average speed based on the data from formula (2). The known 
distance would be given by the distance of monitoring stations (bus stop, entrance, monitoring station at the airport) using the above mentioned technologies from check-in counters and security check points. The following formula (3) can be used to calculate the current time of arrival of passengers to each airport service points:

$$
t_{\text {time of arrival to the post }}=\frac{\text { known distance from ttarger post }}{\text { speed based on pedestrain space }}
$$

Data on time of arrival of passengers to specific airport service point (calculated by the use of formula (2) and (3)) help to optimize distribution of airport staff and achieve smooth flow of passengers in the terminal.

\subsection{Use of the IoT for passenger's purpose.}

If both systems (Smart City and Smart Airport) are connected, commuters have the choice between different travel modes (Ahmed et al., 2020) and they will know exactly which mean of transportation is best to use. The system considers current traffic situation in the city. When choosing a specific type of transportation to the airport, the passenger would be informed of the current mean of transport occupancy and delays, to avoid an overcrowded means of transportation and he/she would be able to use an emptier vehicle (Figure 4).

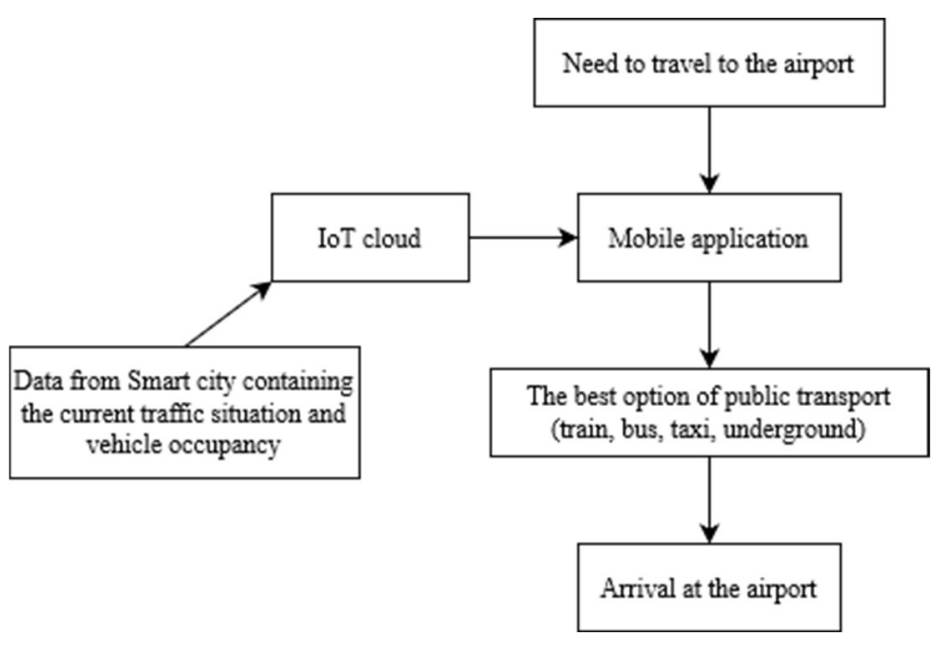

Figure 4: Basic design of the mobile application informing passenger about the best possibilities of transportation to the airport.

Source: Authors.

When it comes to specific airport facilities, passengers are informed where the shortest queues are for e.g., check-in or security control and they also receive information on specific waiting times (Figure 5).

Furthermore, the application could contain an interface that would allow each passenger to navigate through the terminal, where he/she would know the exact route, depending on his location, to individual counters, posts, gates, shops, restaurants, and other airport facilities. Part of this, assuming the use of formula (3), should be the calculation of the estimated arrival at specific point in the terminal. Such a system has already been tested at London Gatwick Airport. It uses a mobile augmented reality system to navigate through 
the airport based on lighthouses (Gatwick Airport, 2018). The advantage of such mobile navigation is that the buildings would become clearer and passengers who are worst in orientation would not get lost.

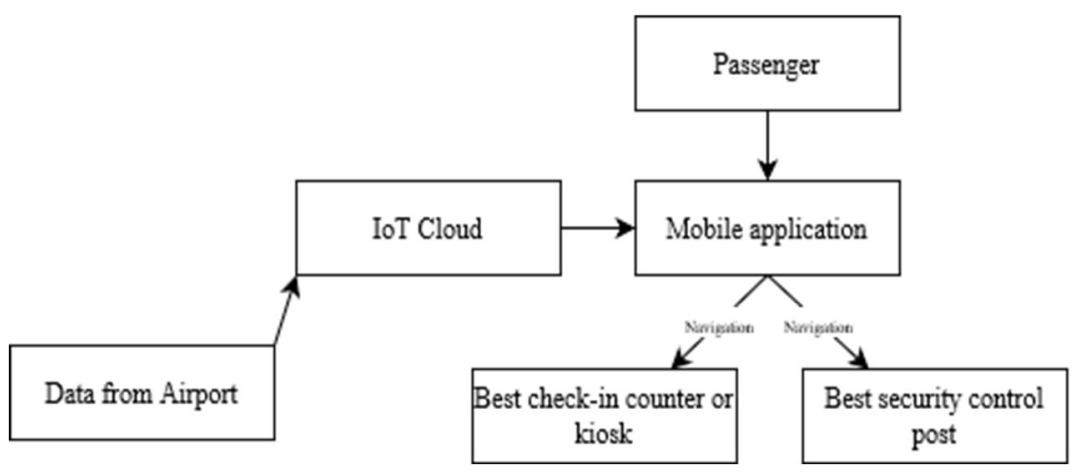

Figure 5: Basic design of the mobile application informing passenger about availability of check-in counters and security check points including navigation at the airport.

Source: Authors.

\section{Solution design}

Based on the input parameters described in section 2, the design of the Smart Airport concept is described in figure 6 . It shows that:

1. The entire management process will be covered by the Airport management system. It will include an interface capable of modeling the optimal use and deployment of staff needed to handle passengers, based on various input data provided by airport, airlines, and smart city.

2. The system will rely on data from IoT sensors located at the airport and in the city.

3. Static data will provide the information on the current occupancy of individual airport points to the airport operator. System will be able to optimize the number of required personnel. The actual terminal throughput is then calculated based on current number of passengers in the terminal. It is then used to calculate the time of arrival of passengers to individual stations.

4. Data (on number of passengers traveling to the airport) will be used to plan number of airport staff needed before they reach the airport.

5. Data from airline reservation systems will be very important for the needs of the airport. Based on the details of each passenger, airport management system will know the exact number of how many of them will use the services of check-in, how many of them will drop-off their luggage and how many of them will go directly to the security check post. 
6. The mobile application will provide way-finding solutions to passengers including estimated walking time. Passengers will be able to check whether their luggage is loaded onto the aircraft, as RFID tags would be used on the luggage. For the needs of transport to and from the airport, the application would inform the passenger of the most suitable means of transportation taking into account current traffic situation and occupancy of particular connection.

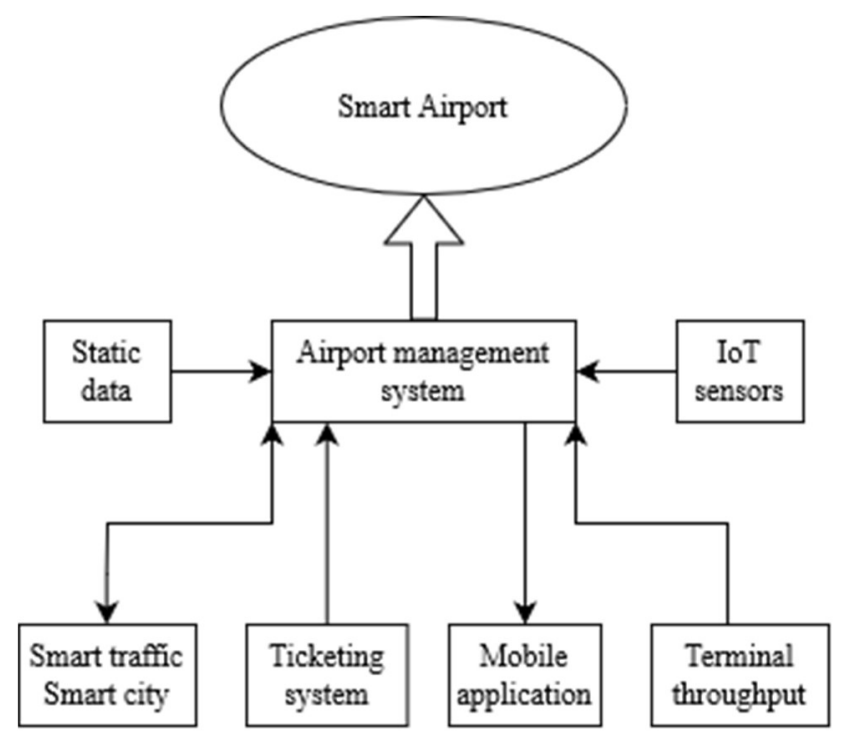

Figure 6: Smart airport system diagram.

Source: Authors.

\section{Results}

The proposed solution presented in section 3 is applied to a sample of 8 international airports. The study discusses the airports in Istanbul, Singapore - Changi, Doha - Hamad, London - Gatwick, Amsterdam - Schiphol, Tokyo - Narita, Seoul - Incheon, Brussels Zaventem. The representative sample represents European and Asian airports. All listed airports are characterized by the use of digital technologies and devices that work on the principle of IoT. Because these airports are using the IoT and other digital technologies, the implementation of the improvements presented by us seems to be feasible.

The research, which is presented in the following tables 2-9, consists in finding the intersection between the available infrastructure at airports and the elements of the implementation of IoT into airport operations. In the case of monitoring the number of people for the needs of optimization of staff, we will talk about crowd monitoring. Improving the baggage handling system will be referred to as RFID. The calculation of the time required to arrive at one station is included in the speed calculation. Finally, all additional services that would make it easier for the passenger to stay at the airport, i.e. navigation, information about occupancy, are included in the term passenger comfort. These elements need certain components to function. The components of the digital infrastructure are the following parts. Sensor systems - represents a system of monitoring sensors for collecting various types of data, specifically for monitoring the number of people in the terminal. Self-check-in points - represent self-check in kiosk, a place where the passenger can independently check-in for the flight and drop off his / her baggage. Component of Airport mobile application represent mobile interface, which has the task 
of comprehensively informing about important and operational events at the airport. NFC technology represent method of capturing various data on chips, tags. Virtual assistants in this case represent interface in mobile application with elements of augmented reality, suitable for navigation. Component of Lost baggage tracking system is defined as a system for tracking lost baggage during the process of checked baggage handling. Personalized orientation can be defined as tool for navigating inside of the terminal to the passenger - selected location. Lastly, Intelligent information system processes the raw data, which is then used to inform passengers and airport staff.

If the infrastructure at the airport is available and suitable for the implementation of the IoT element, the intersection is marked, in order to implement the element. In following tables 2-9 are described selected airports and their digital systems suitable for the use of the proposed smart airport system.

Table 2: Intersection between IoT elements and airport infrastructure components at Istanbul (new) Airport

\begin{tabular}{|c|c|c|c|c|}
\hline \multicolumn{5}{|c|}{ Istanbul (new) Airport } \\
\hline & $\begin{array}{c}\text { Crowd } \\
\text { monitoring }\end{array}$ & $R F I D$ & $\begin{array}{c}\text { Speed } \\
\text { calculation }\end{array}$ & $\begin{array}{c}\text { Passenger } \\
\text { comfort }\end{array}$ \\
\hline Sensor system & $\bullet$ & - & $\bullet$ & $\bullet$ \\
\hline Self-check-in points & $\bullet$ & & & $\bullet$ \\
\hline Airport mobile application & & & & $\bullet$ \\
\hline NFC technology & & - & & \\
\hline Virtual assistants & & & & - \\
\hline Lost baggage tracking system & & $\bullet$ & & \\
\hline Personalized orientation & & & & $\bullet$ \\
\hline Intelligent information system & - & & & - \\
\hline
\end{tabular}

Table 3: Intersection between IoT elements and airport infrastructure components at Singapore Changi Airport

\begin{tabular}{lcccc}
\hline \multicolumn{4}{c}{ Singapore Changi Airport } \\
\hline & $\begin{array}{c}\text { Crowd } \\
\text { monitoring }\end{array}$ & RFID & $\begin{array}{c}\text { Speed } \\
\text { calculation }\end{array}$ & $\begin{array}{c}\text { Passenger } \\
\text { comfort }\end{array}$ \\
\hline $\begin{array}{l}\text { Sensor system } \\
\text { Self-check-in points }\end{array}$ & $\bullet$ & $\bullet$ & $\bullet$ & $\bullet$ \\
Airport mobile application & $\bullet$ & & & $\bullet$ \\
NFC technology & & & \\
Virtual assistants & & & \\
Lost baggage tracking system & & $\bullet$ & \\
$\begin{array}{l}\text { Personalized orientation } \\
\text { Intelligent information system }\end{array}$ & $\bullet$ & & \\
\hline
\end{tabular}


Table 4: Intersection between IoT elements and airport infrastructure components at Doha Hamad Airport

\begin{tabular}{lcccc}
\hline \multicolumn{4}{c}{ Doha Hamad Airport } & \\
\hline & $\begin{array}{c}\text { Crowd } \\
\text { monitoring }\end{array}$ & RFID & $\begin{array}{c}\text { Speed } \\
\text { calculation }\end{array}$ & $\begin{array}{c}\text { Passenger } \\
\text { comfort }\end{array}$ \\
\hline Sensor system & $\bullet$ & $\bullet$ & $\bullet$ & $\bullet$ \\
Self-check-in points & $\bullet$ & & & $\bullet$ \\
Airport mobile application & & & & \\
NFC technology & & & \\
Virtual assistants & & & \\
Lost baggage tracking system & & $\bullet$ & \\
$\begin{array}{l}\text { Personalized orientation } \\
\text { Intelligent information system }\end{array}$ & $\bullet$ & & \\
\hline
\end{tabular}

Table 5: Intersection between IoT elements and airport infrastructure components at London Gatwick Airport

\begin{tabular}{|c|c|c|c|c|}
\hline \multicolumn{5}{|c|}{ London Gatwick Airport } \\
\hline & $\begin{array}{c}\text { Crowd } \\
\text { monitoring }\end{array}$ & $R F I D$ & $\begin{array}{c}\text { Speed } \\
\text { calculation }\end{array}$ & $\begin{array}{c}\text { Passenger } \\
\text { comfort }\end{array}$ \\
\hline Sensor system & $\bullet$ & $\bullet$ & $\bullet$ & $\bullet$ \\
\hline Self-check-in points & $\bullet$ & & & $\bullet$ \\
\hline Airport mobile application & & & & $\bullet$ \\
\hline NFC technology & & $\bullet$ & & \\
\hline Virtual assistants & & & & $\bullet$ \\
\hline Lost baggage tracking system & & $\bullet$ & & \\
\hline Personalized orientation & & & & $\bullet$ \\
\hline Intelligent information system & $\bullet$ & & & $\bullet$ \\
\hline
\end{tabular}

Table 6: Intersection between IoT elements and airport infrastructure components at Amsterdam Schiphol Airport

\begin{tabular}{lcccc}
\hline \multicolumn{4}{c}{ Amsterdam Schiphol Airport } \\
\hline & $\begin{array}{c}\text { Crowd } \\
\text { monitoring }\end{array}$ & RFID & $\begin{array}{c}\text { Speed } \\
\text { calculation }\end{array}$ & $\begin{array}{c}\text { Passenger } \\
\text { comfort }\end{array}$ \\
\hline Sensor system & $\bullet$ & $\bullet$ & $\bullet$ & $\bullet$ \\
Self-check-in points & $\bullet$ & & $\bullet$ \\
Airport mobile application & & & $\bullet$ \\
NFC technology & & & $\bullet$ \\
Virtual assistants & & & \\
Lost baggage tracking system & & & $\bullet$ \\
Personalized orientation & & & $\bullet$ \\
Intelligent information system & $\bullet$ & & \\
\hline
\end{tabular}


Table 7: Intersection between IoT elements and airport infrastructure components at Tokyo Narita Airport

\begin{tabular}{|c|c|c|c|c|}
\hline \multicolumn{5}{|c|}{ Tokyo Narita Airport } \\
\hline & $\begin{array}{c}\text { Crowd } \\
\text { monitoring }\end{array}$ & RFID & $\begin{array}{c}\text { Speed } \\
\text { calculation }\end{array}$ & $\begin{array}{c}\text { Passenger } \\
\text { comfort }\end{array}$ \\
\hline Sensor system & $\bullet$ & • & $\bullet$ & $\bullet$ \\
\hline Self-check-in points & • & & & - \\
\hline Airport mobile application & & & & $\bullet$ \\
\hline NFC technology & & $\bullet$ & & \\
\hline Virtual assistants & & & & $\bullet$ \\
\hline Lost baggage tracking system & & $\bullet$ & & \\
\hline Personalized orientation & & & & • \\
\hline Intelligent information system & • & & & $\bullet$ \\
\hline
\end{tabular}

Table 8: Intersection between IoT elements and airport infrastructure components at Seoul Incheon Airport

\begin{tabular}{lcccc}
\hline \multicolumn{5}{c}{ Seoul Incheon Airport } \\
\hline & $\begin{array}{c}\text { Crowd } \\
\text { monitoring }\end{array}$ & RFID & $\begin{array}{c}\text { Speed } \\
\text { calculation }\end{array}$ & $\begin{array}{c}\text { Passenger } \\
\text { comfort }\end{array}$ \\
\hline Sensor system & $\bullet$ & $\bullet$ & $\bullet$ & $\bullet$ \\
Self-check-in points & $\bullet$ & & $\bullet$ \\
Airport mobile application & & & $\bullet$ \\
NFC technology & & & $\bullet$ \\
Virtual assistants & & & \\
Lost baggage tracking system & & & $\bullet$ \\
Personalized orientation & & & $\bullet$ \\
Intelligent information system & $\bullet$ & & \\
\hline
\end{tabular}

Table 9: Intersection between IoT elements and airport infrastructure components at Brussels Zaventem Airport

\begin{tabular}{lcccc}
\hline \multicolumn{5}{c}{ Brussels Zaventem Airport } \\
\hline & $\begin{array}{c}\text { Crowd } \\
\text { monitoring }\end{array}$ & RFID & $\begin{array}{c}\text { Speed } \\
\text { calculation }\end{array}$ & $\begin{array}{c}\text { Passenger } \\
\text { comfort }\end{array}$ \\
\hline Sensor system & $\bullet$ & $\bullet$ & $\bullet$ & $\bullet$ \\
Self-check-in points & $\bullet$ & & $\bullet$ \\
Airport mobile application & & & $\bullet$ \\
NFC technology & & & \\
Virtual assistants & & & \\
Lost baggage tracking system & & & $\bullet$ \\
Personalized orientation & & & $\bullet$ \\
Intelligent information system & $\bullet$ & & \\
\hline
\end{tabular}

The analysis shows that each airport has smart systems in place that would be suitable for the proposed concepts. At sample airports, it is possible to implement crowd monitoring for the needs of optimal redistribution of staff whose tasks are to handle passengers. Furthermore, these airports have technology that is suitable for the introduction of RFID tags on baggage, so there would be an improvement and 
streamlining of the baggage handling process. A sufficient network of sensors located at selected airports can provide information on the speed and distance of passengers from individual stations, so that the estimated time of arrival of a passenger can be calculated. The latest indicator is technologies that would increase passenger comfort. They have enough sensors, systems and applications that can provide additional information for passengers. Thus, navigation around the airport, occupancy station and calculation of arrival time at a specific station. The only exception is Singapore Changi Airport, which does not have Smart Assistants, we assume that in this case it would be necessary to create an application to mediate such messages.

\section{Discussion}

Complex airport management systems require considerable technical equipment, which can represent a significant financial burden, especially for small airports. With the current pandemic situation, it is difficult for the airports to introduce or continue their investments because it is predicted that the recovery phase will take a lot of time (Serrano and Kazda, 2020). Exact price is now very difficult to predict, as there are a number of smart devices available on the market with different prices and parameters. What may suit for one airport may not suit for another airport and this can significantly affect the price.

One of the issues that needs to be tackled in the future is the issue of data sharing and access to data by all involved stakeholders. It may possibly happen that some users will refuse to provide their location data, and the overall information may then appear incomplete.

Because the whole system would work on the basis of the Internet and many devices would be connected to it, there will be a need to build a robust firewall protection system capable of resisting various hacker attacks. Therefore, we suggest that the data for airports consist only of location data and data on the need for services used at the airport (baggage / check-in).

There are couple of suggestions that the authors are able to propose. Such a complex system should be tested at small airports Once a certain integrity of the system has been achieved, deployment could take place at larger airports. However, research has shown that large airports are sufficiently equipped to run such a system at least in a test run. However, we must not forget that the introduction of such a system will require mass introduction of smart technologies in cities.

This solution design also brings many benefits for the airport and passengers. Based on real-time data, the airport operator will be able to prepare for the arrival of passengers and it will be able to properly allocate staff for passenger handling service. As all data is collected in the IoT cloud, it is possible to work and analyze the data for several days in advance and, depending on the expected volume of passengers, operator can additionally make changes in the number of employees needed to serve passengers. This means that in the case of a larger volume, more employees may be called to work, and in the case of a smaller volume of passengers, especially at night and outside peak hours, there may be fewer employees at work. These changes could lead to a partial saving in salary costs.

When using passenger tracking in the terminals by any of the mentioned methods, we see another benefit. Especially in various emergency situations. In the event of a breach of security by passenger, the security authority could determine, based on position, exactly where the threat is located and thus eliminate it more quickly. This method can also be used for suspected passengers who have not yet committed any crime to monitor them preventively and not rely only on camera recordings. 
From the passenger's point of view, this will speed up the total handling time, because passengers spend less time waiting in queues. Such time savings are more advantageous for the passenger and he can use it for other more pleasant things. Built-in augmented reality navigation also prevents situations where passengers get lost at the airport and do not show up for a flight due to a miss. Thus, for ground handling of aircraft, there is less risk that the luggage of a passenger who has missed a flight would have to be removed from the loaded aircraft again.

\section{Conclusion}

Due to the importance of airport management system, several applications have been proposed in this area. Therefore, in this paper, analyzes an airport management system solution based on the IoT. From the point of view of this paper, commissioning of the Smart airport concept seems to be a viable solution, as smart devices (mobiles) would be used to obtain data, which are more and more popular, and most people already own them. However, an obstacle to this system is the construction of a complex monitoring network in cities and airports as well as systems enabling work with data. Monitoring the location of people and working with personal data can also be a problem. Therefore, this concept also requires the legislation.

This designed Smart Airport system improves the following processes:

1. Transport to the airport will be much clearer thanks to the mobile application and will offer information on occupancy and the use of the most convenient means,

2. Check-in processes at airports would become much faster due to the optimal use of airport staff and the optimal opening of individual checkpoints due to work with real-time data on the number of people heading to the airport or already directly at the airport,

3. The augmented reality system would navigate passengers and visitors in the terminals using their smart devices (mobile, tablet, ...),

4. Individual urban transport companies can also benefit from such a concept. Based on the number of arriving passengers, they could optimally expand the capacity of the means of transport from the airport to the city.

In the current COVID-19 pandemic situation, the provision of information on the occupancy of individual means of transport and the number of people at airport's posts (check-in, security control, shops, restaurants, gates, ...) can be considered as very beneficial. Practical examples show that experts recommend to people not accumulate on small places or recommend limit the number of people in a certain place, mainly to prevent the spread of the virus.

The future direction of this research would lead to the creation of a larger representative sample of airports, which would be able to identify the potential for the implementation of the airport management system and the actual traffic data obtained on passenger behavior can then be used for further study to create various predictive models.

\section{References}

ACI (2013) "Recommended Practice 300¹2: Manual Measurement of Passenger Service Process Time and KPI's", available online: https://aci.aero/Media/c3e17fa9-b3914b30-ba88-07004d2b2b37/LG-_qg/About\%20ACI/Priorities/Facilitation/ManualMeasurement-of-Passenger-Service-Process-Time-and-KPIs.pdf (accessed on 4.6.2021). 
Ahmed, A. et al. (2020) "Modelling Behaviour of Shuttle Service Users and Preference towards a Proposed Bus Rapid Transit Line", European Transport $\backslash$ Trasporti Europei 79, ISSN 1825-3997.

AlMashari, R. et al. (2018) "IoT-based Smart Airport Solution", Proceedings from the 2018 International Conference on Smart Communications and Networking (SmartNets), (Y. Hammamet), Tunisia, pp. 1-6.

Alodhaibi, S., Burdett R. L., Yarlagadda, P. K. D. V. (2019) “Impact of Passenger-Arrival Patterns in Outbound Processed of Airports", Procedia Manufacturing 30. Pp. 323330 .

Ashford, N., Munayit, S.A, Wright, P.H. (2011) Airport engineering: planning, design, and development of 21 st century airport, Wiley, New Jersey.

Atzori, L., Iera, A., Morabito, G. (2009) "The Internet of Things: A survey", Computer Networks 54 (15), pp. 2787-2805.

Baskoro, H. et al. (2017) "Design considerations of RFID based baggage handling system, a literature review", Proceedings from the International Conference on Information Management and Technology (ICIMTech), Yogyakarta, pp. 210-214.

Bouyakoub, S. (2017) "Smart airport: an IoT-base Airport Management System", ICFNDS ' 17 - Proceedings of the International Conference on Future Networks and Distributed Systems, pp. 1-7.

Cheng, L. (2014) "Modelling airport passenger group dynamics using an agent-based method", Masters by Research thesis. Queensland University of Technology

Chaudary, M. (2016) "Finding occupancy in buses using crowdsourced data from smartphones", ICDCN'16 - Proceedings from the $17^{\text {th }}$ International Conference on Distributed Computing and Networking, pp. 1-4.

Correia, A. R. (2008) "Overall level of service measures for airport passenger terminals", Transportation Research Part A: Policy and Practice 42 (2), pp. 330-346.

Gatwick Airport (2020) "IT", [online] Available at: https://www.gatwickairport.com/business-community/careers/meet-our-teams/it/

IATA (2019) "Resolution: RFID Baggage Tracking Set for Global Depoyment", available online: https://www.iata.org/en/pressroom/pr/2019-06-02-05/ (accessed on 3.6.2021).

ICES (2016) "Passenger-oriented smart airport services: a system design and implementation", Harbin Institute of Technology.

International Telecommunications Union (2005) "ITU Internet Reports 2005: The Internet of Things. Executive Summary".

Koman, G. et al. (2018) "Possibilities of Application a Big Data in the Company Innovation Porcess", Communications in Computer and Information Science 887, pp. 646-657.

Kotopouleas, A., Nikolopoulou, M. (2018) "Evaluation of comfort conditions in airport terminal buildings", Building and Environment 130, pp. 162-178.

Lee, H.-J., Lyu, J. (2019) "Exploring factors which motivate older consumers' selfservice technologies (SSTs) adoption", International Review of Retail, Distribution and Consumer Research 29 (2), pp. 218-239.

Mat'aš, M., Novák, A. (2008) "Models of Processes as Components of Air Passenger Flow Model", Communications - Scientific Letter of the University of Zilina 10 (2), pp. 50-54. 
Meuter, M.L. et al. (2000) "Self-service technologies: Understanding customer satisfaction with technology-based service encounters", Journal of Marketing 64 (3), pp. 50-64

Morrison, W. G. (2009) "Understanding the complexities and challenges of airport performance benchmarking", Journal of Airport Management 3 (2), pp. 145-158.

Ni, J. et al. (2018) "Securing Fog Computing for Internet of Things Applications: Challenges and Solutions", IEEE Communications Surveys and Tutorials 20 (1), pp. 601-628.

Samy, H. (2017) "Studying traveler's use of self check-in technologies in smart airports", Journal of Association of Arab Universities for Tourism and Hospitality 14 (1), pp. 79-90.

Serrano, F., Kazda, A. (2020) "The future of airports post COVID-19", Journal of Air Transport Management 89.

SITA (2011) “The Intelligent airport", Société International de Telecommunication Aéronautique.

Štefánik, M. (2009) “Airport Landside Capacity: Making Airports Intermodal Transport Nodes".

TECHNATIVE (2017) "Trasportation 4.0: Providing Door-to-Door Travel in Multimodal System", available online: https://technative.io/transport-4-0-providingdoor-to-door-travel-in-a-multimodal-transportation-system/ (accessed on 5.6.2021).

Want, R. (2006) “An Introduction to RFID Technology”, IEE Pervasive Computing 5 (1), pp. 25-33. 